\title{
Modelling the Suitability of Pine Sawdust for Energy Production via Biomass Steam Explosion
}

\author{
Zephania Chaula $^{{ }^{*}}$, Mahir Said ${ }^{2}$, Geoffrey John ${ }^{1}$, Samwel Manyele ${ }^{3}$, Cuthbert Mhilu ${ }^{2}$ \\ ${ }^{1}$ Department of Sustainable Energy Science and Engineering, The Nelson Mandela African Institute of Science and Technology, \\ Arusha, Tanzania; ${ }^{2}$ Department of Mechanical and Industrial Engineering and Technology, University of Dar es Salam, Dar es Sa- \\ laam, Tanzania; ${ }^{3}$ Department of Chemical and Mining Engineering, University of Dar es Salam, Dar es Salam, Tanzania. \\ Email: “chaulaz@nm-aist.ac.tz, mahir@udsm.ac.tz, geofrey.john@nm-aist.ac.tz, smanyele@udsm.ac.tz, cfmhilu@hotmail.com
}

Received November $4^{\text {th }}$, 2013; revised December $4^{\text {th }}$, 2013; accepted December $11^{\text {th }}, 2013$

Copyright (C) 2014 Zephania Chaula et al. This is an open access article distributed under the Creative Commons Attribution License, which permits unrestricted use, distribution, and reproduction in any medium, provided the original work is properly cited. In accordance of the Creative Commons Attribution License all Copyrights (C) 2014 are reserved for SCIRP and the owner of the intellectual property Zephania Chaula et al. All Copyright (C) 2014 are guarded by law and by SCIRP as a guardian.

\section{ABSTRACT}

Biomass material as a source of fuel is difficult to handle, transport, store, and utilize in its original form. To overcome these challenges and make it suitable for energy prodution, the material must be pre-treated. Biomass steam explosion is one of the promising pretreatment methods where moisture and hemicellulose are removed in order to improve biomass storage and fuel properties. This paper is aimed to model the suitability of pine saw dust for energy production through steam explosion process. The peak property method was used to determine the kinetic parameters. The model has shown that suitable operating conditions for steam explosion process to remove moisture and hemicellulose from pine sawdust. The temperature and pressure ranges attained in the current study are $260-317^{\circ} \mathrm{C}(533$ - $590 \mathrm{~K}), 4.7$ - 10.8 MPa, respectively.

\section{KEYWORDS}

\section{Biomass Pretreatment; Hemicellulose; Kinetics; Pine Sawdust; Steam Explosion}

\section{Introduction}

The abundance of biomass and its renewable nature make it a promising alternative to conventional fossil fuels, but the natural characteristics of biomass compared to fossil fuels create problems for energy suitability. One of the problems associated with biomass is its hygroscopic nature and moisture content that have a considerable effect on the biomass energy suitability.

The high moisture content in biomass will impact the overall feasibility of the energy production by the following way: More water content tends to lower heating value. Furthermore automation systems can not react to rapid variations in moisture content resulting in incomplete combustion. In addition, the presence of moisture in the biomass absorbs part of heat liberated during the combustion process and increases heat loss from the stack [1]. When biomass contains sulfur, the risk of $\mathrm{H}_{2} \mathrm{SO}_{4}$ corrosion on heat recovery unit is increased in

${ }^{*}$ Corresponding author. induced draft fan, ducting and chimney.

In order to make biomass suitable for use in current energy production facilities, pretreatments are required to be performed on the biomass to upgrade its fuel quality. Simulation calculation of the transformation process of the biomass pyrolysis can be more convenient and more quickly to recognize the characteristics of the biomass pyrolysis than test, and it has a very important significance in developing the technology of simulation calculation of the transformation process and achieving the efficient use of the biomass energy. One of the pretreatment methods is the removal of moisture and hemicellulose in order to improve quality and shelf life of biomass. Pretreatment of biomass aims to decrease crystallinity of cellulose, increase biomass surface area, remove hemicellulose, and break the lignin barrier as shown in Figure 1. Since many biomasses have different physical and chemical characteristics, it is necessary to deploy suitable pretreatment technology based on their properties.

The removal of moisture and hemicellulose from bio- 


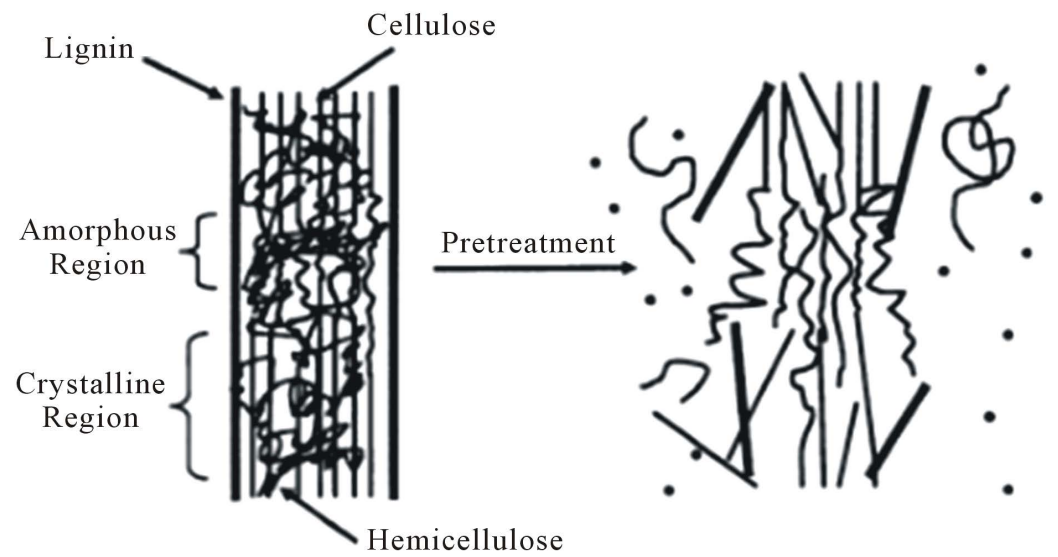

Figure 1. Effect of biomass pretreatment [3].

mass is a thermal process that results in high biomass fuel quality. The biomass porosity increases, and since the hydrophilic groups have been destroyed due to the removal of hemicelluloses, the remaining biomass material would not be able to absorb water due to the increase of storage stability of biomass fuel [2,3].

Hemicelluloses are known as the most thermally unstable biomass component. Bourgeois in [4] reported that the degradation of hemicelluloses increases with temperature and residence time between $225^{\circ} \mathrm{C}$ (498 K) and $325^{\circ} \mathrm{C}(598 \mathrm{~K})$. Cellulose degradation occurs at higher temperatures, because of its crystalline structure. It degrades in a temperature range of $325^{\circ} \mathrm{C}-375^{\circ} \mathrm{C}(598$ $648 \mathrm{~K})$ [5].

Amongst the major components of the cell wall, lignin is the most thermally stable one, although lignin degradation stretches over a wide temperature range starting at $180^{\circ} \mathrm{C}-500^{\circ} \mathrm{C}(453-773 \mathrm{~K})$ [6]. Volatile matters are released at temperatures above $450^{\circ} \mathrm{C}-500^{\circ} \mathrm{C}(723-773$ $\mathrm{K})$ and the remaining material is char [7].

Carter, in [8] studied the physicochemical properties and thermal decomposition of torrefied woody biomass and energy crop. In the study, it was observed that the torrefied woody biomass did not contain hemicellulose. The steam explosion treatment upgrades the biomass by removing volatiles, which results in increasing the low heating value of biomass from 17 to $23 \mathrm{MJ} / \mathrm{kg}$ [9]. Also, the hygroscpic nature of biomass is lost, which contributes to the destruction of $\mathrm{OH}$-groups and prevents the formation of hydrogen bonding. Therefore, the final product becomes non-polar [9].

The aim of this paper is to model the suitability of pine sawdust for energy production via biomass steam exlossion. The model will provide suitable conditions such as temperature and pressure for hemicellulose decomposition. The model will not consider the removal of moisture from pine sawdust. Due to the hygroscopic nature of biomass, the moisture evaporates at lower temperature below $150^{\circ} \mathrm{C}$ (423 K) [8]. Also, moisture removal can be observed during thermal-gravimetric analysis of pine sawdust.

\section{Chacteristics of Hemicellulose Decomposition}

1) Kinetic study

TGA has been used to model the kinetic decomposition reactions of hemicellulose. The decomposition rate is expressed by Arrhenius Equation (1) [10].

Where $A$ is the pre-exponential factor, $E$ is the activation energy, and $R$ is universal gas constant.

The chemical kinetic parameters were determined by the peak property method (PPM) developed by Kim in [11]. In it, the peak temperature $\left(T_{m}\right)$, peak height $\left(H_{m}\right)$, and conversion at peak temperature $\left(\alpha_{m}\right)$ from the DTG curve are used to estimate the kinetic parameters, activation energy $(E)$ and pre-exponential factor $(A)$ of a reaction. The thermolysis of solid state biomass is described by the conversion process from raw material to char and volatiles. The decomposition process is described by the chemical reaction rate and the Arrhenius law considering the decomposition process as a one-stage chemical reaction. The rate of decomposition is determined by the temperature $(T)$, and the quantity of reactant, given by:

$$
\frac{\mathrm{d} \alpha}{\mathrm{d} t}=k(T) f(\alpha)
$$

where $\alpha$ is the conversion of decomposing material, $k(T)$ is the rate constant depends on temperature, and $f(\alpha)$ represents a conversion function as effect of reactant quantity to the reaction rate.

The function $f(\alpha)$ is expressed as,

$$
f(\alpha)=(1-\alpha)^{n}
$$

where $n$ is the reaction order, while the function $k(T)$ is described by Arrhenius equation, shown is Equation (1).

During thermolysis process, at a constant heating rate $(\beta)$, 


$$
\frac{\mathrm{d} T}{\mathrm{~d} t}=\beta
$$

Rearranging Equations (1) to (4), gives,

$$
\frac{\mathrm{d} \alpha}{\mathrm{d} T}=\frac{A}{\beta} \exp \left(-\frac{E}{R T}\right)(1-\alpha)^{n}
$$

At a peak temperature, the derivative of Equation (5) with respect to temperature, yields zero and allows the following relationship:

$$
\frac{E}{n R T_{m}^{2}\left(1-\alpha_{m}\right)^{n-1}}=\frac{A}{\beta} \exp \left(-\frac{E}{R T_{m}}\right)
$$

On the other hand, peak height, $H_{m}$, is described by:

$$
H_{m}=\frac{A}{\beta} \exp \left(-\frac{E}{R T_{m}}\right)\left(1-\alpha_{m}\right)^{n}
$$

Combining Equations (6) and (7), $E$ and $A$ correlate with the three peak properties $\left(T_{m}, H_{m}\right.$, and $\left.\alpha_{m}\right)$ as follows:

$$
\begin{gathered}
E=\frac{n R T_{m}^{2} H_{m}}{\left(1-\alpha_{m}\right)} \\
A=\frac{H_{m} \beta \exp \left(E / R T_{m}\right)}{\left(1-\alpha_{m}\right)^{n}}
\end{gathered}
$$

Using Equations (8) and (9), $E$ and $A$ is estimated.

2) Modeling of hemicellulose decomposition

The decomposition of hemicellulose in biomass material is altered by operating temperature and heating rate. Di Blasi in [5] reported that hemicellulose decomposes at a temperature range of $225^{\circ} \mathrm{C}(498 \mathrm{~K})$ to $325^{\circ} \mathrm{C}(598 \mathrm{~K})$ at a heating rate of $10 \mathrm{~K} / \mathrm{min}$. As heating rate is increased, the range of degradation temperature of the hemicellulose becomes relatively narrow.

The simultaneous evolvement of other components can not be avoided during hemicellulose decomposition, which depends on biomass characteristics and the severity of the conversion conditions. Furthermore, when removing hemicellulose from biomass through thermal degradation, the effects of secondary reaction should be kept at a minimum level. This is done so as to avoid the decomposition of cellulose and lignin. To keep secondary reaction at a minimum level the operating temperature is set below $327^{\circ} \mathrm{C}(600 \mathrm{~K})$ [5].

The mechanism proposed by Bradbury in [12] is applicable for hemicellulose decomposition from biomass. This model is known as multicomponent mechanism of primary pyrolysis. The reaction rates presenting the Arrhenius dependence on temperature is the first order in the reactant mass fraction. The kinetic constants of hemicellulose decomposition shown in Table 1 are derived from [5].

\section{Materials and Methods}

The biomass samples used in this study was obtained from Sanya Juu forest, West Kilimanjaro, in Tanzania. Standard test methods were adopted for establishing the following parameters:

\subsection{Calorific Value}

American Standard ASTM D4809 was deployed to determine the gross calorific value of the sample by using a standard bomb calorimeter type Wagtech Gallenkamp Autobomb.

\subsection{Proximate Analysis}

The proximate analysis of the samples were determined by using furnace (model Nobertherm P330 SN 224344), The standard method deployed was ASTM 3172.

Table 1. Kinetic mechanism and constants for hemicellulose.

$\begin{aligned} k_{1} & =2.10 \times 10^{6} \exp \left(-\frac{186.7}{R T}\right) \\ k_{2} & =8.75 \times 10^{15} \exp \left(-\frac{202.4}{R T}\right) \\ k_{3} & =2.60 \times 10^{11} \exp \left(-\frac{145.7}{R T}\right) \\ v_{c} & =0.6\end{aligned}$




\subsection{Ultimate Analysis}

The ultimate analysis were conducted to determine Carbon, Hydrogen, Nitrogen and Sulfur $(\mathrm{C}, \mathrm{H}, \mathrm{N}, \mathrm{S})$ at ASTM standards (E775, E777, E778 ). The oxygen (O) composition was calculated by difference.

\subsection{Thermo-Gravimetric Analysis (TGA)}

The thermo-gravimetric analyzer used in this study was NETZSCH STA 409 PC Luxx. Prior to thermo-gravimetric experiments, a sample was grounded to small particles $(<1 \mathrm{~mm})$ and then oven dried at $105^{\circ} \mathrm{C}(378 \mathrm{~K})$ to a constant weight for removing the moisture. Thereafter a $30 \mathrm{mg}$ sample was heated under inert nitrogen $(99.95 \%$ purity) condition at a heating rate of $10 \mathrm{~K} / \mathrm{min}$ from room temperature to $727^{\circ} \mathrm{C}(1000 \mathrm{~K})$, the experiments were repeated 5 times and arithmetic mean values are reported.

\section{Results and Discussion}

\subsection{Proximate Analysis}

Fixed carbon, ash and volatile matter on percentage weight of biomass and calorific value are depicted in Table 2. Moisture and sulfur content of the biomass are also given. The amount of moisture contained in this sample is about $19.0 \% \mathrm{wt}$; this is medium moisture contained in the biomass as per [13] scale of 16 to $40 \mathrm{wt} \%$.

\subsection{Ultimate Analysis}

The carbon and hydrogen are 48.71 and 5.99 wt\% respectively, these are the main components for combustion of biomass. The oxygen content is $44.2 \mathrm{wt} \%$, this reduces the energy content of biomass [14]. The calorific value of biomass can be increased by reducing the oxygen content through pretreatment of biomass, since the pretreatment of biomass through steam explosion reduces oxygen to carbon ratio [15].

Table 2. Proximate and ultimate analysis of pine sawdust.

\begin{tabular}{cc}
\hline \multicolumn{2}{c}{ Proximate Analysis, dry basis (\%wt) } \\
\hline Moisture & 18.84 \\
Volatile Matter & 81.03 \\
Fixed Carbon & 18.60 \\
Ash & 0.37 \\
\hline Ultimate Analysis (\%wt) \\
\hline Carbon & 48.71 \\
Hydrogen & 5.99 \\
Oxygen & 44.2 \\
Nitrogen & 2.39 \\
Sulfur & 0.28 \\
HHV MJ/kg & 15.096 \\
\hline
\end{tabular}

The elemental composition of pine saw dust has low sulfur $0.28 \%$ and nitrogen $2.39 \%$ content than that of fossil fuel such as coal $1.71 \%$ and $1.39 \%$ as reported by [16]; this will be associated low formation of $\mathrm{SO}_{\mathrm{X}}$ and $\mathrm{NO}_{\mathrm{X}}$ during combustion of such fuel than that of coal. It is therefore beneficial to the environment when using pine saw dust for energy production.

\subsection{Thermal Behavior}

Figure 2 shows the TG and DTG curves of thermal decomposition of pine saw dust. From TG profile, the first weight loss corresponds to the moisture loss, at temperature below $150^{\circ} \mathrm{C}(423 \mathrm{~K})$ in the sample. The second weight reduction corresponding to the increase of temperature to $600^{\circ} \mathrm{C}(873 \mathrm{~K})$ which is attributed to devolatilisation and pyrolysis of hemicelluloses, cellulose and lignin. All the volatiles were evolved at a range of 150 to $600^{\circ} \mathrm{C}$ (423 to $873 \mathrm{~K}$ ), and only char remained. In this step, the yields of the volatile material were up to $77.11 \%$ of the initial weight of sample. The observed char was $2.36 \mathrm{wt} \%$.

The DTG curve exhibited maximum weight loss rate at a temperature range of $260^{\circ} \mathrm{C}-370^{\circ} \mathrm{C}(533-643 \mathrm{~K})$, at this temperature range hemicellulose and cellulose decomposed. The hemicellulose decomposed at a temperature range of $260^{\circ} \mathrm{C}-340^{\circ} \mathrm{C}(533-613 \mathrm{~K})$, which associated with the shoulder of second peak of the DTG curve, while the cellulose associated with the peak at a temperature range of $320^{\circ} \mathrm{C}-380^{\circ} \mathrm{C}$. The lignin decomposed slowly over a very broad range of temperature from $300^{\circ} \mathrm{C}-580^{\circ} \mathrm{C}(573-853 \mathrm{~K})$. Since almost all temperature ranges of hemicellulose, cellulose and lignin overlap with each other during their decomposition, they are labelled as pseudocomponents.

During the process of pretreatment of pine saw dust for removal of moisture and hemicellulose a temperature and corresponding saturated steam pressure of $260^{\circ} \mathrm{C}$ (533 K) and 4.7 Mpa respectively are required as a minimum and it should not exceed $320^{\circ} \mathrm{C}(593 \mathrm{~K})$ and saturated pressure of 10.8 MPa in order to avoid decom- position of cellulose and lignin. The saturated pressure for decomposition of hemicellulose are obtained from steam table.

The steam at saturated pressure of 4.7 - 10.8 MPa is suitable for pretreatment of biomass, because the only biomass component that is unstable at this saturated steam pressure is hemicellulose while lignin and cellulose are stable. This results show good agreement with the review of Stelte in [17], who reported that the steam explosion is operated at pressure between 3.5 to $7 \mathrm{MPa}$.

\subsection{Kinetics of Thermal Decomposition}

Differential thermalgravimetric (DTG) curve presented 


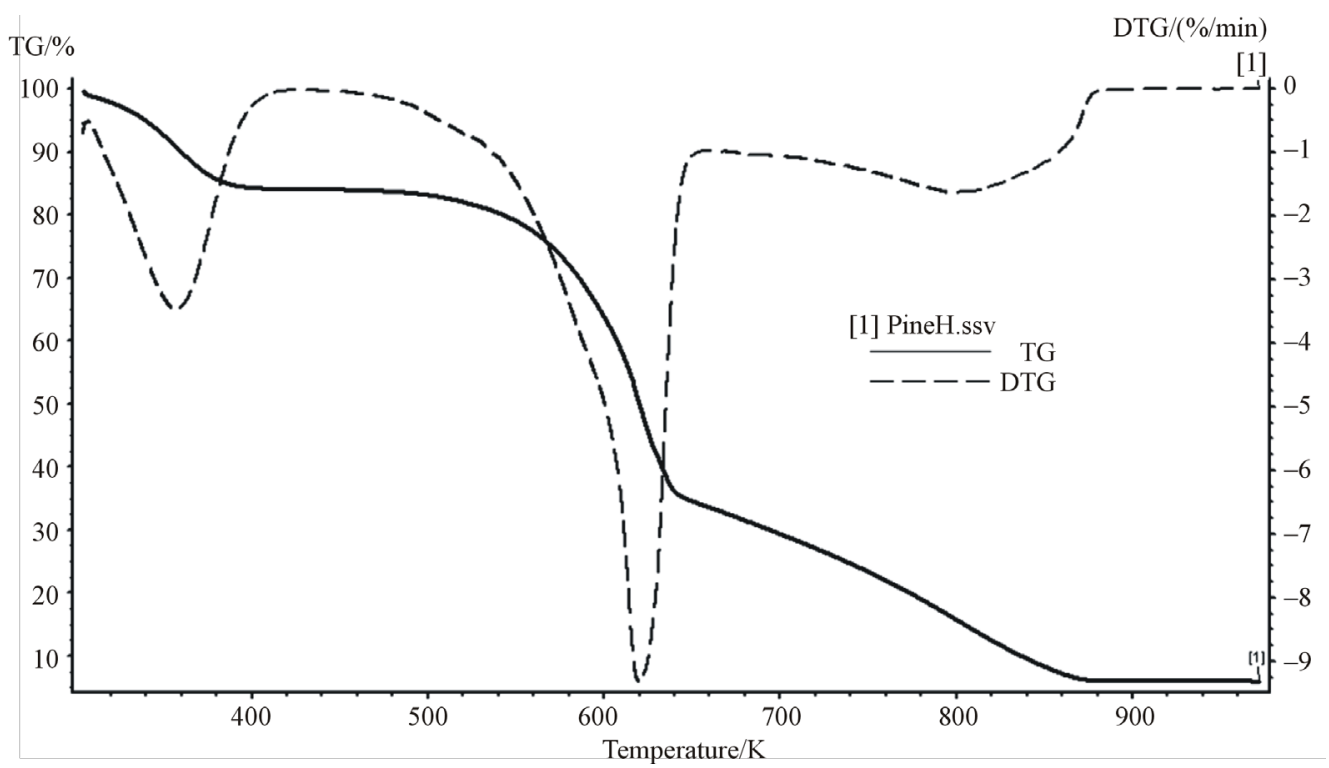

Figure 2. TG and DTG curves for pine sawdust at $10 \mathrm{~K} / \mathrm{min}$ heating rate.

in Figure 2 for pine saw dust, obtained at heating rate of $10 \mathrm{~K} / \mathrm{min}$. From this DTG curve, the determined three peak properties of hemicellulose $(\mathrm{Tm}, \mathrm{Hm}, \mathrm{\alpha m})$ were $320^{\circ} \mathrm{C}(593 \mathrm{~K}), 0.04 \mathrm{~K}^{-1}$, and 0.55 respectively, as shown in Table 3. Assuming the decomposing volatiles obey first order kinetic reaction. According to Equations (8 and 9) and the experimental data, the kinetic parameters; activation energy (E) and pre exponential factor (A) were $259.876 \mathrm{~kJ} / \mathrm{mol}$ and $4.365 \times 10^{23} \mathrm{~s}^{-1}$, respectively.

Figure 3 shows the reaction speed with increasing of temperature during biomass components reaction. Hemicellulose decomposed faster than cellulose and lignin, at low temperature below $287^{\circ} \mathrm{C}(560 \mathrm{~K})$ the rate of decomposion of all biomass components was slow, while above $287^{\circ} \mathrm{C}(560 \mathrm{~K})$, the rate of decomposition of hemicellulose was exponentially faster than others. The decomposition of cellulose started at $337^{\circ} \mathrm{C}(610 \mathrm{~K})$, but lignin did not decompose. This shows that it is easier to remove hemicellulose at low temperature than cellulose and lignin Hemicellulose decomposed gradually from $227^{\circ} \mathrm{C}(500 \mathrm{~K})$ to $287^{\circ} \mathrm{C}(560 \mathrm{~K})$, as shown in Figure 4. Three products were obtained; char, tar and gas. At $317^{\circ} \mathrm{C}(590 \mathrm{~K})$ char production was at peak (43 wt $\left.\%\right)$, gas was $29 \mathrm{wt} \%$ and tar was $25 \mathrm{wt} \%$.

By increasing temperature more than $317^{\circ} \mathrm{C}(590 \mathrm{~K})$, the tar yield was increasing while char yield was decreasing and gas yield was constant. Therefore, the optimum temperature for the decomposition of hemicellulose and for the high char yield is $317^{\circ} \mathrm{C}(590 \mathrm{~K})$.

\section{Conclusions}

Pine saw dust was characterized for useful application in energy production. The results will help design the op-
Table 3. Kinetic parameters of pine sawdust.

\begin{tabular}{cccc}
\hline \multirow{2}{*}{ Parameter } & \multicolumn{3}{c}{ Pine sawdust composite } \\
\cline { 2 - 4 } & Hemicellulose & Cellulose & Lignin \\
\hline Peak temperature $(\mathrm{Tm})$ & $317^{\circ} \mathrm{C}$ & $350^{\circ} \mathrm{C}$ & $510^{\circ} \mathrm{C}$ \\
$(590 \mathrm{~K})$ & $(623 \mathrm{~K})$ & $(783 \mathrm{~K})$ \\
Peak height $(\mathrm{Hm}, \mathrm{K}-1)$ & 0.04 & 0.078 & 0.015 \\
$\begin{array}{c}\text { Conversion at peak } \\
\text { temperature }(\alpha \mathrm{m})\end{array}$ & 0.55 & 0.45 & 0.1 \\
$\begin{array}{c}\text { Activation energy } \\
(\mathrm{E}, \mathrm{kJ} / \mathrm{mol})\end{array}$ & 259.876 & 457.644 & 89.95 \\
$\begin{array}{c}\text { Pre-exponential factor } \\
\left(\mathrm{A}, \mathrm{s}^{-1}\right)\end{array}$ & $4.365 \times 1023$ & $3.33 \times 1038$ & $1.768 \times 105$ \\
\begin{tabular}{c} 
Reaction constant $\left(\mathrm{k}, \mathrm{s}^{-1}\right)$ \\
\hline
\end{tabular} & 5.596 & 1.414 & 0.167 \\
\hline
\end{tabular}

timal steam explosion treatment process. The moisture content was $18.84 \mathrm{wt} \%$, which is medium moisture content.

The activation energy for hemicellulose was 259.876 $\mathrm{kJ} / \mathrm{mol}$ at a peak temperature of $317^{\circ} \mathrm{C}(590 \mathrm{~K})$, and the hemicellulose decomposed earlier than cellulose and lignin.

The temperature range of $260^{\circ} \mathrm{C}-317^{\circ} \mathrm{C}(533$ - $590 \mathrm{~K})$ and corresponding pressure of $4.7-10.8 \mathrm{MPa}$ are suitable operating conditions for steam explosion pretreatment process of pine sawdust to remove moisture and hemicellulose. The temperature and pressure are useful for designing and optimization of chemical reactors.

The rate of decomposition of hemicellulose is faster than that of cellulose and lignin. Lignin is decomposing slowly during thermal decomposition at a broder range of temperature of $300^{\circ} \mathrm{C}-580^{\circ} \mathrm{C}(573-853 \mathrm{~K})$.

The characterization and modeling of pine saw dust show that pine saw dust is suitable material for energy production via steam explosion, since hemicellulose and 


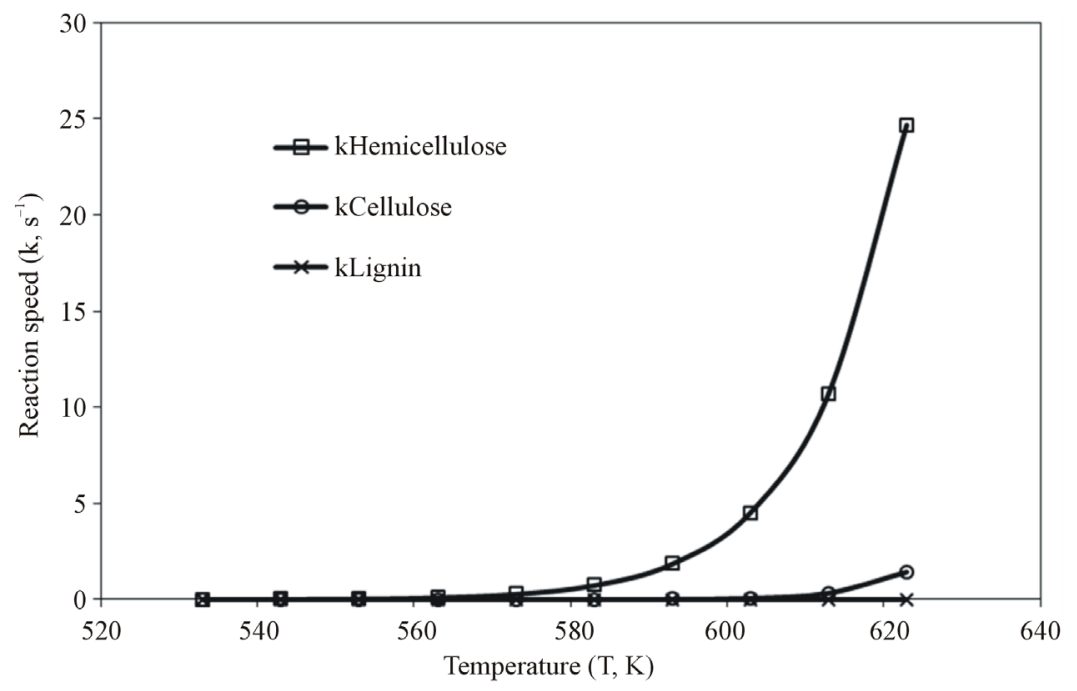

Figure 3. Variation of reaction constant with temperature.

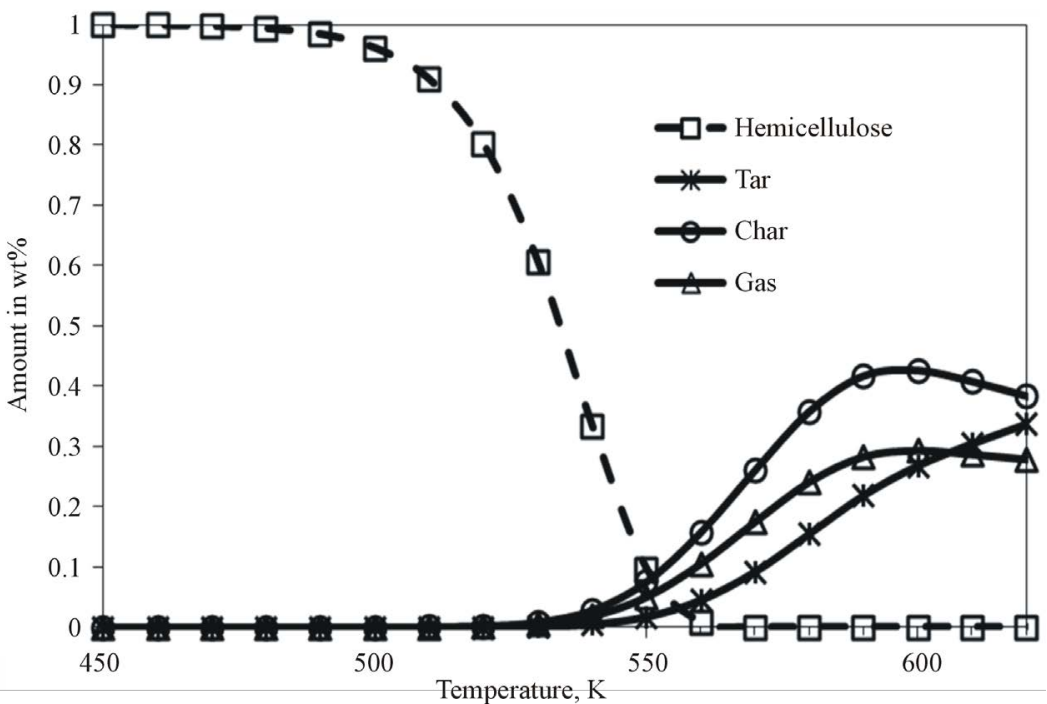

Figure 4. The decomposition of hemicellulose.

moisture are removed without decomposing cellulose and lignin. Water and hemicellulose decomposed at lower temperature below $317^{\circ} \mathrm{C}(590 \mathrm{~K})$, whilst cellulose and lignin decomposed at temperatures in excess of $347^{\circ} \mathrm{C}$ $(620 \mathrm{~K})$.

\section{Acknowledgement}

The authors wish to thank The Nelson Mandela African Institution of Science and Technology and Commission for Science and Technology, Tanzania for their generous financial and materials support rendered to allow this research work to be conducted.

\section{REFERENCES}

[1] B. Livingston and M. Babcock, "Ash Related Issues in
Biomass Combustion,” Thermal Net Workshop Proceedings, Glasgow, 2006.

[2] G. Mtui, "Recent Advancres in Pretreatment of Lignocellulosic Wastes and Production of Value Added Products,” African Journal of Biotechnology, Vol. 8, 2009, pp. 1398-1415.

[3] P. Harmsen, W. Huijgen, L. Bermudez and R. Bakker, "Liturature Review of Physical and Chemical Pretreatment Processes for Lignocellulosic Biomass,” Energy Reserch Center of the Netherlands, 2010.

[4] J. Bourgeois, M. Bartholin and R. Guyonnet, "Thermal Treatment of Wood: Analysis of the Obtained Product," Wood Science and Technology, Vol. 23, No. 4, 1989, pp 303-310. http://dx.doi.org/10.1007/BF00353246

[5] C. Di Blasi, "Modeling Chemical and Physical Processes of Wood and Biomass Pyrolysis," Journal Progress in Energy and Combustion Science, Vol. 34, No. 1, 2008, pp. 
47-90. http://dx.doi.org/10.1016/j.pecs.2006.12.001

[6] C. Hill, "Wood Modification: Chemical, Thermal and Other Processes,” John Wiley \& Sons Ltd, Chichester, 2006. http://dx.doi.org/10.1002/0470021748

[7] F. Beall and H. Eickener, "Thermal Degradation of Wood Components: A Review of the Literature," U.S.D.A. Forest Service Research Paper, Forest Products Laboratory Service 130, 1970.

[8] C. Carter, "Physicochemical Properties and Thermal Decomposition of Torrefied Woody Biomass and Energy Crop," Thesis for the Degree of Master of Science, Auburn, 2012.

[9] P. Bergman, “Torrefaction for Biomass Upgrading," 14th Europian Biomass Conference and Exhibition, Paris 2005.

[10] A. Tsamba, "Fundermental Study of Two Selected Tropical Biomass for Energy: Coconut and Cashew Shells," Doctoral Thesis in Energy and Furnace Technology, KTH, Stockholm, 2008.

[11] S. Kim, E. Jang, D. Shinb and K. Lee, "Using Peak Properties of a DTG Curve to Estimate the Kinetic Parameters of the Pyrolysis Reaction: Application to High Density Polyethylene,” Journal of Polymer Degradation and Stability, Vol. 85, No. 2, 2004, pp. 799-805.

\section{Nomenclature}

A-Pre-exponential factor $\left(\mathrm{s}^{-1}\right)$

$E$-Activation energy $(\mathrm{kJ} / \mathrm{mol})$

$f(\alpha)$-Conversion function(-)

$H_{m}$-Height of the peak(-)

$k$-Reaction constant $\left(\mathrm{s}^{-1}\right)$

$n$-Order of reaction http://dx.doi.org/10.1016/j.polymdegradstab.2004.03.009

[12] A. Bradbury, S. Yoshio and F. Shafizadeh, "A Kinetic Model for Pyrolysis of Cellulose," Journal of Applied Polymer Science, Vol. 23, No. 11, 1979, pp. 3271-3280. http://dx.doi.org/10.1002/app.1979.070231112

[13] R. Parmar, M. Welling, M. Andreae and G. Helas, "Water Vapor Release from Biomass Combustion,” Atmospheric Chemistry and Physics, Vol. 8, 2008, pp. 6147-6153. http://dx.doi.org/10.5194/acp-8-6147-2008

[14] P. Basu, "Biomass Gasification and Pyrolysis Practical Design and Theory,” Elservier, Oxford, 2010.

[15] A. Biswas, "Thermochemical Behavior of Pretreated Biomass," Licentiate Thesis in Energy and Furnace Technology, KTH, Stockholm, 2012.

[16] M. Mann and P. Spath, “A Life Cycle Assessment of Biomass Co-Firing in a Coal-Fired Power Plant,” Journal of Clean Production Processes, Vol. 3, No. 2, 2001, pp. 81-91. http://dx.doi.org/10.1007/s100980100109

[17] W. Stelte, "Steam Explosion for Biomass Pretreatment, Energy and Climate,” Centre for Renewable Energy and Transport Section for Biomass, Danish Technological Institute, 2013.

$R$-Universal gas constant $(\mathrm{J} / \mathrm{mol} \mathrm{K})$

$\mathrm{T}$-Temperature $\left({ }^{\circ} \mathrm{C}\right.$ and $\left.\mathrm{K}\right)$

$t$-Time (s)

$T_{m}$-Peak temperature $\left({ }^{\circ} \mathrm{C}\right.$ and $\mathrm{K}$ )

$\alpha$-Degree of conversion (-)

$\beta$-Heating rate $(\mathrm{K} / \mathrm{min})$ 